\title{
Endophytic fungal community in grape is correlated to foliar age and domestication
}

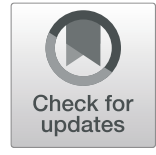

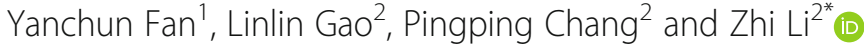

\begin{abstract}
Purpose: The composition of endophytic communities has been shown to depend on grape genotypes and viticultural managements in leaves, stems, and berries of grape, but there have been relatively few reports exploring fungal endophytes associated with wild grape and foliar age.

Methods: The regions of internally transcribed spacer (ITS) were sequenced using the Illumina HiSeq to determine the diversity of fungal endophytes associated with European grape (Vitis vinifera cv. Red Globe) and Chinese wild grape (Vitis amurensis cv. Shuangyou) in young and mature leaves.

Results: A total of 3 phyla, 23 classes, 51 orders, 97 families, and 150 fungal genera were identified. Young leaves have significantly higher diversity and richness than that in mature leaves in both cultivars. Endophytic fungal diversity was greater in wild grapevines (119 genera) than in cultivated grapevines (81 genera) in both young and mature leaves. Endophytic fungal community structure was also significantly different between young leaves and mature leaves as well as in both cultivars based on statistical tests of ANOSIM and MRPP.

Conclusions: Our results suggest that endophytic fungal communities were strongly affected by foliar age and domestication, which are crucial factors in establishing symbiotic associations with a selective enrichment for specific endophytes.
\end{abstract}

Keywords: Wild grapevine, Endophytic fungi, Community, Foliar age

\section{Introduction}

Endophytes are organisms living within plant tissues and often provide beneficial effects to their hosts, without causing any disease symptoms. Endophytic colonization may protect plants from pathogen attack (Kuldau and Bacon 2008) and environmental stresses (Baltruschat et al. 2008; Sherameti et al. 2008), fix nitrogen (Dixon and Hartmann 2017), and increase host growth (Bae et al. 2009; Varma et al. 1999). However, the establishment of an endophytic fungal species largely depends on host genotype (Horton et al. 2014), sampling site (González and Tello 2011), the developmental stage of host (Oono et al. 2015), the leaf age (Arnold et al. 2003), and the environmental

\footnotetext{
* Correspondence: lizhi@nwsuaf.edu.cn

${ }^{2}$ State Key Laboratory of Crop Stress Biology in Arid Areas, College of Horticulture, Northwest A\&F University, Yangling 712100, Shaanxi, China Full list of author information is available at the end of the article
}

contexts (Pancher et al. 2012) such as seasons (Sadeghi et al. 2019), average temperature, annual rainfall, and latitude (Arnold and Lutzoni 2007).

The endophytic diversity is associated with host genotype. However, most the studies that investigated the diversity of endophytic fungal communities in grapevines mainly focused on Vitis vinifera cultivars (Casieri et al. 2009; González and Tello 2011; Martini et al. 2009; Pancher et al. 2012), whereas comparisons of endophytic communities between cultivars and Chinese wild grape are scant. Chinese wild grape germplasms have been identified as highly resistant to multiple pathogenic fungi (Wan et al. 2015; Wang et al. 1995; Yu et al. 2013). The elucidation of endophytic fungal species diversity between cultivars and wild grape genotypes of grapevine will help us understand the domestication and host specificity, as well as distribution, frequency, and beneficial effects of endophytes.

(c) The Author(s). 2020 Open Access This article is licensed under a Creative Commons Attribution 4.0 International License, which permits use, sharing, adaptation, distribution and reproduction in any medium or format, as long as you give appropriate credit to the original author(s) and the source, provide a link to the Creative Commons licence, and indicate if changes were made. The images or other third party material in this article are included in the article's Creative Commons licence, unless indicated otherwise in a credit line to the material. If material is not included in the article's Creative Commons licence and your intended use is not permitted by statutory regulation or exceeds the permitted use, you will need to obtain permission directly from the copyright holder. To view a copy of this licence, visit http://creativecommons.org/licenses/by/4.0/. 
Endophytic fungal communities are also likely to be correlated with plant age including seedlings (Oono et al. 2015) and leaves (Sanchez-Azofeifa et al. 2012) at different stages of development. Comparisons of endophyte communities across leaf age are helpful for an in depth understanding of the interaction between endophytic fungi and leaf characteristics, including leaf physiology and leaf development. It was reported in previous studies that endophytic fungal species richness and diversity could vary according to the age of the leaves from an increase to no difference or an initial increase and then decrease in species richness (Arnold et al. 2003; Espinosa Garcia and Langenheim 1990; Fróhlich et al. 2000; López-González et al. 2017; Sanchez-Azofeifa et al. 2012). Therefore, studying the effects of different foliar ages on fungal endophyte communities will provide clues about the recruitment and accumulation of species along foliar development under natural conditions in grapes.

Little information is known about how endophytic fungal community is affected by cultivated grape and wild grape. This is why we have decided to study foliar endophytes. A comprehensive study of foliar fungal endophytes associated with Chinese wild grape (Vitis amurensis) and European grape ( $V$. vinifera) in young and mature leaves under their natural environment is lacking. Therefore, we determined the relative abundance and diversity of foliar endophytes of Chinese and European grapes and evaluated the effect of leaf age on the colonization frequency, species richness, and diversity of the endophytic community. Our study provides an important baseline to further expand the ecological understanding of foliar fungal endophytes in grape.

\section{Materials and methods}

\section{Plant species and study site}

This study utilized 3-year-old grape plants grown in the germplasm nursery of Northwest A\&F University, Shaanxi, China (latitude $=34.16$, longitude $=108.07$, annual precipitation $=635.1-663.9 \mathrm{~mm}$, annual average temperature $=12.9^{\circ} \mathrm{C}$ ). The soil in the nursery contains $1.02 \mathrm{~g} / \mathrm{kg}$ total nitrogen, $1.03 \mathrm{~g} / \mathrm{kg}$ total phosphorus, and $40.22 \mathrm{~g} / \mathrm{kg}$ total potassium, with an average $\mathrm{pH}$ of 8.5 . Grape plants were asexually propagated and spaced 2-4 $\mathrm{m}$. All grape plants were periodically sprayed with fungicide and insecticide products such as lime sulfur, Bordeaux mixture, deltamethrin, and dimethoate. Two genotypes, $V$. vinifera cv. Red Globe and $V$. amurensis cv. Shuangyou, were used in this study.

\section{Sampling}

Asymptomatic leaves from two cultivars were collected respectively from the second or third node and the seventh or eighth node from the shoot apex respectively for young leaves and mature leaves (Fig. 1). A total of 20 complete leaves were randomly chosen and pooled from five grape plants for each cultivar at different foliar ages; each assay was repeated five times in the summer of 2017 to provide biological replicates. All leaves were washed thrice with sterile water to eliminate epiphytes, immersed in $3 \%$ sodium hypochlorite for surface sterilization, and then washed again thrice with sterile water. To check the efficacy of this method of surface sterilization, random surface sterilized leaves were incubated on potato dextrose agar (PDA) plates to check for the absence of colony growth from the outside (Dissanayake et al. 2018).

\section{DNA extraction and sequencing}

Each sample was frozen with liquid nitrogen and extracted with DNeasy Plant Mini Kit (Qiagen) according to the manufacturer's instructions. These DNA samples were quantified using a NanoDrop spectrophotometer (NanoDrop Technologies, Wilmington, DE, USA). The primer used for fungal ITS amplification were ITS1-F (CTTGGTCATTTAGAGGAAGTAA) and ITS2 (GCTGCGTTCTTCATCGATGC) (White et al. 1990). PCR protocols were performed according to a previously described method (Pancher et al. 2012). PCR products were purified with QIAquick PCR Purification Kit (Qiagen, Valencia, CA, USA) and then quantified with Quant-iT PicoGreen Kit (Invitrogen, Grand Island, NY, USA). The amplicons were sequenced on an Illumina HiSeq (Illumina Inc., San Diego, CA, USA).

\section{Data processing}

Raw sequence reads were processed using FLASH v1.2.7 (Magoč and Salzberg 2011) and filtered with QIIME 1.8.0 (Caporaso et al. 2010). Sequencing adapters were removed from raw reads of each sample, and the chimeric sequences were deleted from the remaining sequences with USEARCH 6.1 algorithm (Edgar et al. 2011). Reads were checked by average quality score (20 and 30) to identify regions of low sequence quality and then clustered into operational taxonomic units (OTUs) using Uparse v7.0.1001 with a threshold of 97\% identity (Edgar 2013). Each representative sequence of each OTU sequence was blasted with National Center for Biotechnology Information (NCBI) and UNITE database (Abarenkov et al. 2010). Alpha and beta diversity values were calculated using relative abundance as the number of sequences representing each OTU. The Shannon diversity index and the non-parametric Chaol index were performed with the QIIME (Caporaso et al. 2010) to quantify endophytic fungal diversity and richness, respectively. Comparison between cultivars and foliar ages was performed through a principal coordinate analysis (PCoA) calculated using weighted Unifrac distance 


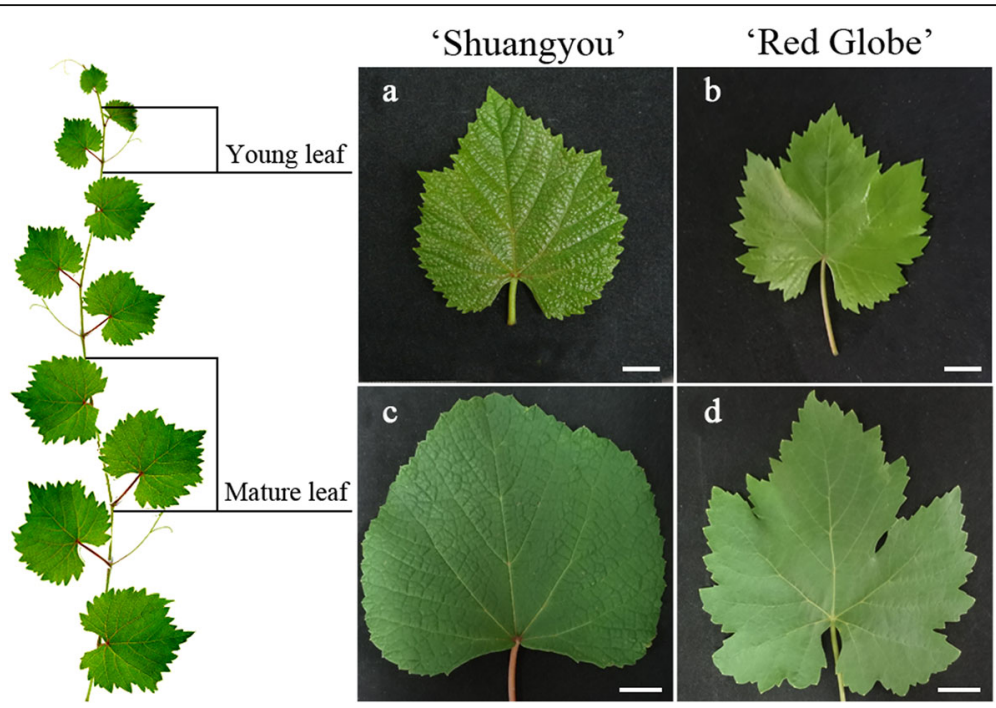

Fig. 1 Foliar morphology of young $(\mathbf{a}, \mathbf{b})$ and mature leaves $(\mathbf{c}, \mathbf{d})$ from $V$. vinifera $c v$. Red Globe and $V$. amurensis $c v$. Shuangyou. Bars: $\mathbf{a}, \mathbf{b}=1$ $\mathrm{cm}, \mathbf{c}, \mathbf{d}=2 \mathrm{~cm}$

(Chen et al. 2012). Two different statistical approaches, ANOSIM (analysis of similarity) and MRPP (multiple-response permutation procedure), were used to test the community structure of endophytic fungus among $V$. vinifera and $V$. amurensis of young and mature leaves. Significant differences were assessed by testing for the least significant difference $(P<0.05)$ and noted in the text or figure captions.

\section{Results}

General characterization of endophytic fungal community After quality filtering, a total of 727,074 reads of the original 775,440 reads were obtained with an average length of 238.7 bp (Table S1). As shown in the rarefaction curves, all of the samples reached saturation with at least 4000 sequences, suggesting that the majority of the operational taxonomic units (OTUs) were recovered in this study (Fig. S1). In total, 198 OTUs were assessed for taxonomic affiliation. Ascomycota was the dominant phylum and accounted for $62.36 \%$ of all OTUs, followed by Basidiomycota (21.57\%) and Zygomycota (2.10\%) (Table 1). Ascomycota has several taxonomic orders, such as Eurotiales $(12.89 \%$ OTUs), Capnodiales (8.15\% OTUs), Hypocreales (7.89\% OTUs), and Pleosporales (7.89\% OTUs), which represented the majority of OTUs; Agaricales (3.15\% OTUs), Malasseziales (3.15\% OTUs), Sporidiobolales (3.15\% OTUs), and Polyporales (2.63\% OTUs) were the most abundant order in the Basidiomycota. A total of 150 endophytic fungal genera were identified as the closest hits of individual OTUs. The ten most abundant endophytic fungal genera were Aspergillus, Penicillium, Rhodotorula, Candida, Fusarium,
Table 1 Taxonomic distribution of OTUs making up phyla and orders of endophytic fungi in $V$. vinifera (Red Globe) and $V$. amurensis (Shuangyou)

\begin{tabular}{|c|c|c|}
\hline Phylum & Order & $\%$ OTU \\
\hline \multirow[t]{10}{*}{ Ascomycota } & & 62.36 \\
\hline & Eurotiales & 12.89 \\
\hline & Capnodiales & 8.15 \\
\hline & Hypocreales & 7.89 \\
\hline & Pleosporales & 7.89 \\
\hline & Sordariales & 2.63 \\
\hline & Saccharomycetales & 2.10 \\
\hline & Incertae sedis & 4.47 \\
\hline & Unidentified & 4.47 \\
\hline & Other Ascomycota ${ }^{a}$ & 11.84 \\
\hline \multirow[t]{8}{*}{ Basidiomycota } & & 21.57 \\
\hline & Agaricales & 3.15 \\
\hline & Malasseziales & 3.15 \\
\hline & Sporidiobolales & 2.63 \\
\hline & Polyporales & 2.63 \\
\hline & Filobasidiales & 1.84 \\
\hline & Russulales & 1.84 \\
\hline & Other Basidiomycota ${ }^{b}$ & 6.31 \\
\hline \multirow[t]{3}{*}{ Zygomycota } & & 2.10 \\
\hline & Mortierellales & 1.31 \\
\hline & Mucorales & 0.78 \\
\hline
\end{tabular}

ancludes orders Xylariales, Microascales, Pezizales, Botryosphaeriales, Lecanorales, Chaetosphaeriales of the phylum Ascomycota

bIncludes orders Erythrobasidiales, Cantharellales, Auriculariales, Cystofilobasidiales, Agaricostilbales of the phylum Basidiomycota 
Pyrenochaetopsis, Gibellulopsis, Amorphotheca, Cladosporium, and Simplicillium (Fig. 2).

\section{Differences in endophytic fungal communities between foliar ages}

Endophytic fungal diversity differed significantly between foliar ages $(P<0.05)$, and endophytic fungal diversity in young leaves was higher than mature leaves in $V$. vinifera cv. Red Globe and $V$. amurensis cv. Shuangyou based on Shannon index and Chao 1 index (Fig. 3). PCoA revealed that the compositions of all samples were clustered into three groups, suggesting partial overlap for young leaves and obvious difference for mature leaves between two grape hosts (Fig. S2). Two non-parametric multivariate statistical tests, ANOSIM and MRPP, showed that the endophytic fungal community structures of young and mature leaves were significantly different in both cultivars (Table 2). In all 150 endophytic fungal genera, 65 fungal genera were associated with young leaves and 30 fungal genera were associated with mature leaves in 'Red Globe' (RG), whereas 90 were associated with young leaves and 67 with mature leaves in 'Shuangyou' (SY) (Fig. S3). Aspergillus and Fusarium were the most dominant genera in young leaves of RG and SY, whereas Gibellulopsis and Mycosphaerellaceae reached the highest relative abundance values in mature leaves (Table S2).

\section{Differences in endophytic fungal communities between cultivars}

Community structure of endophytic fungi in SY was significantly different from RG. Similar results were also obtained in the mature leaves of both cultivars, whereas no significant difference was observed in young leaves (Table 2). In total, 150 foliar fungal endophytes at genus level were identified in both cultivars, in which $20 \%$ and $46 \%$ non-overlapped endophytic fungi of the total endophytic were detected in RG and SY, respectively (Fig. 4a; Table S3). The genera of Gibellulopsis, Aspergillus, Cladosporium, and Malassezia were significantly less abundant in SY than in the RG in 50 overlapped endophytic fungi (Fig. 4b). Hyphoderma, Oedocephalum, Lambertella, and Phialosimplex genus were the most abundant in RG, whereas Pyrenochaetopsis, Montagnulaceae, and Phoma genus were the most abundant in SY (Fig. 4c).

\section{Discussion}

The endophytic fungal community associated with grape leaves was mainly composed of fungi belonging to the phylum Ascomycota with a small proportion of the phyla Basidiomycota and Zygomycota. The dominance of endophytic Ascomycota in the leaves has been documented in many plant species, such as Arabidopsis thaliana (García et al. 2013), loblolly pine (Oono et al. 2015), lima bean (López-González et al. 2017), and in grape (González and Tello 2011). Within Ascomycota, the three most detected classes were Dothideomycetes, followed by Eurotiomycetes and Sordariomycetes, which have shown to be the main components in other woody plants (Materatski et al. 2019). At genus level in grape, most fungi in this study are already known as grape endophytes and found in similar abundances in previous reports, such as high abundant genus of Aspergillus, Penicillium, Cladosporium, and Fusarium and low

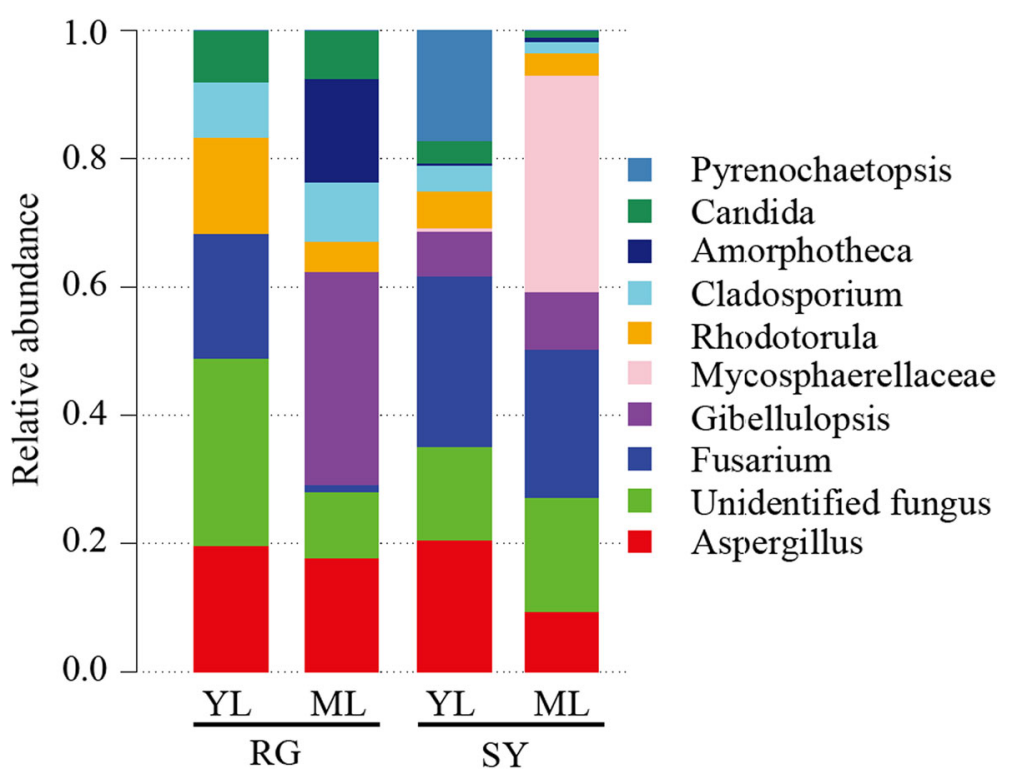

Fig. 2 Relative abundance of fungi identified as endophytes in grape samples at genus level. Stacked bar plots represent mean relative abundances of fugal endophytes within genera. 

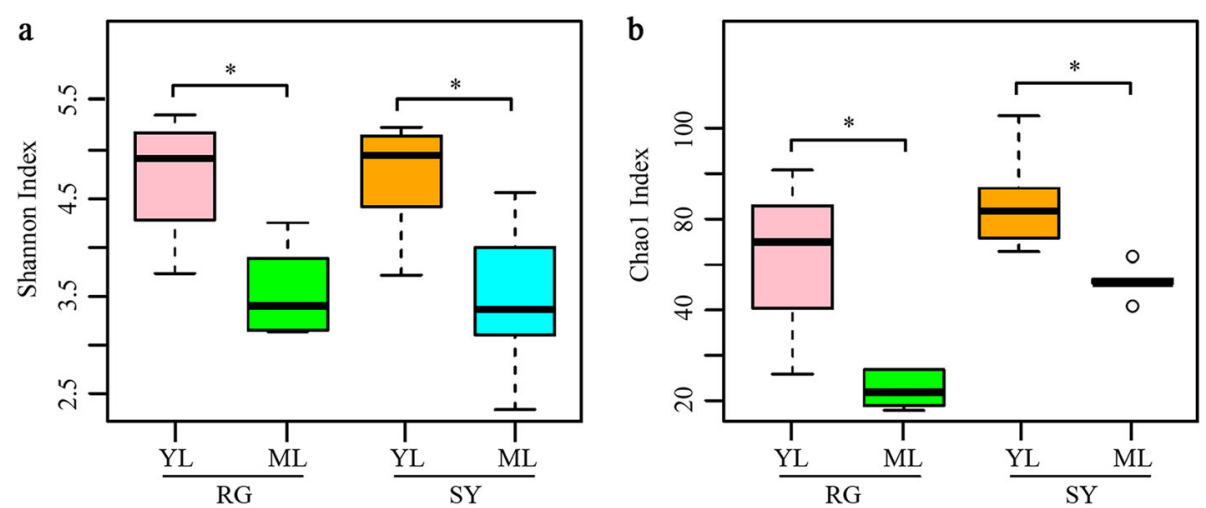

Fig. 3 Endophytic fungal diversity across foliar ages collected from V. vinifera cv. Red Globe and V. amurensis cv. Shuangyou. Four independent samples were used to calculate the values for richness based on Shannon index (a) and Chaol index (b). Asterisks indicate statistically significant differences $(P<0.05)$. RG, V. vinifera cv. Red Globe; SY, V. amurensis Cv. Shuangyou; YL, young leaves; ML, mature leaves

abundance genus of Gibberella and Phoma (González and Tello 2011; Pancher et al. 2012).

The number of species of fungal endophytes in wild grape $V$. amurensis cv. Shuangyou was higher than in $V$. vinifera cv. Red Globe both in young and mature leaves (Fig. S3). Kernaghan et al. (2017)' s study found similar patterns as ours, suggesting that foliar fungal endophytes from wild populations of Vitis riparia have higher

Table 2 Community structure of endophytic fungus among $V$. vinifera (Red Globe) and V. amurensis (Shuangyou) at young and mature stages tested by ANOSIM and MRPP

\begin{tabular}{|c|c|c|c|c|}
\hline \multicolumn{5}{|l|}{ ANOSIM $^{a}$} \\
\hline $\begin{array}{l}\text { Samples } \\
\text { characteristics }\end{array}$ & \multicolumn{2}{|c|}{$R$ value } & \multicolumn{2}{|l|}{$P$ value } \\
\hline$R G Y L$ - RG ML & \multicolumn{2}{|l|}{0.73} & \multicolumn{2}{|l|}{0.013} \\
\hline SY YL - SY ML & \multicolumn{2}{|l|}{0.44} & \multicolumn{2}{|l|}{0.022} \\
\hline$R G Y L-S Y Y L$ & \multicolumn{2}{|l|}{0.11} & \multicolumn{2}{|l|}{0.168 (ns) } \\
\hline RG ML - SY ML & \multicolumn{2}{|l|}{0.83} & \multicolumn{2}{|l|}{0.007} \\
\hline$R G$ - SY & \multicolumn{2}{|l|}{0.28} & \multicolumn{2}{|l|}{0.007} \\
\hline \multicolumn{5}{|l|}{ MRPP ${ }^{b}$} \\
\hline $\begin{array}{l}\text { Samples } \\
\text { characteristics }\end{array}$ & $\begin{array}{l}A \\
\text { value }\end{array}$ & $\begin{array}{l}\text { Observed } \\
\text { delta }\end{array}$ & $\begin{array}{l}\text { Expected } \\
\text { delta }\end{array}$ & $P$ value \\
\hline$R G Y L-R G M L$ & 0.09 & 0.70 & 0.78 & 0.007 \\
\hline SY YL - SY ML & 0.04 & 0.73 & 0.76 & 0.037 \\
\hline RG YL - SY YL & 0.008 & 0.78 & 0.79 & $\begin{array}{l}0.186 \\
\text { (ns) }\end{array}$ \\
\hline RG ML - SY ML & 0.11 & 0.66 & 0.75 & 0.009 \\
\hline RG - SY & 0.03 & 0.77 & 0.80 & 0.005 \\
\hline
\end{tabular}

Significance with $P<0.05$ is indicated in bold (ns, not significant) $R G$ V. vinifera cv. Red Globe, SY V. amurensis cv. Shuangyou, YL young leaves, $M L$ mature leaves

${ }^{a}$ Analysis of similarity (ANOSIM) indicates the degree of difference between groups, where $R$ value closer to 1 indicates that no members are shared, and $R$ value closer to 0 indicates that communities are identical

${ }^{\mathrm{b}}$ Multiple response permutation procedure (MRPP) returns a delta value representative of the observed versus permuted within-group distances richness and diversity than hybrid Vitis (Kernaghan et al. 2017). In addition, the diversity of endophytic bacteria was also greater in wild than in domesticated grapevines (Campisano et al. 2015). Compared to cultivated grapes, this higher endophyte diversity in wild grapes may be due to different living environment, fungicide treatments, defense traits, and higher general biodiversity in a wild environment (Campisano et al. 2015). Fungicide treatments can possibly result in changes in fungal species composition and decrease endophyte colonization (Nettles et al. 2016).

Our results clearly show that the richness and diversity of the endophytic fungal community in young leaves were significantly higher than that in mature leaves for both cultivars. Similar patterns were found in other woody plants (Oono et al. 2015); this finding suggests that the diversity of the endophytic fungal community decreased with plant age (Espinosa Garcia and Langenheim 1990). A similar behavior has also been found in mycorrhizal communities (Husband et al. 2002). Conversely, a recent study showed that endophytic fungal community tends to expand with foliar age in lima bean (López-González et al. 2017). This discrepancy can be due to the differential specificity of woody plants and herbaceous plants to endophytic species. The changes of endophytic fungal diversity may be concerned with foliar physiology. This phenomenon has been documented; for example, carbohydrates, phosphorus, and phenolic compound utilization are related to microbial community (Lin et al. 2014; Kolton et al. 2017). Broeckling (2008)'s study found that root exudates of Arabidopsis thaliana and Medicago truncatula influenced the fungal community, suggesting fungal diversity is associated with physiological metabolism of plants. In addition, young leaves may have poor structural barriers in 


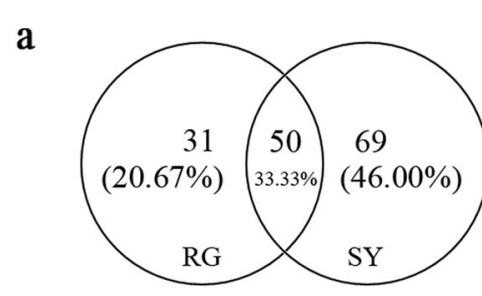

b

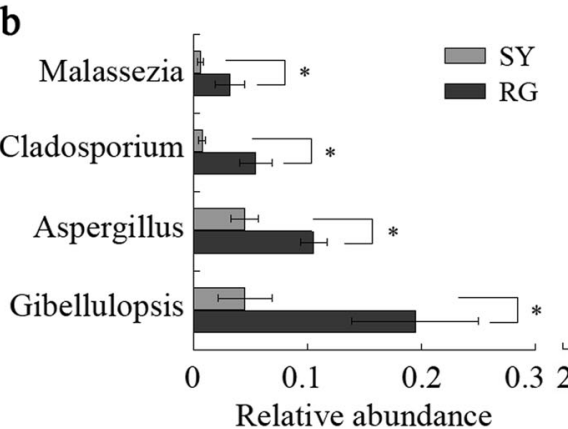

\section{c}

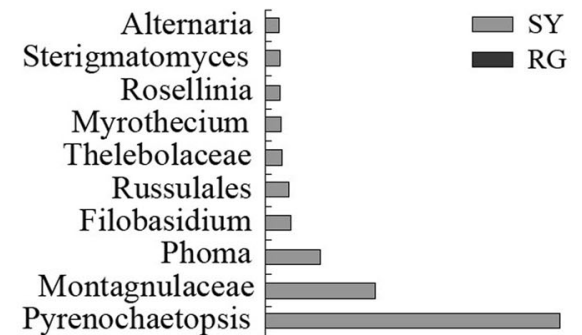

Pyrenochaetopsis

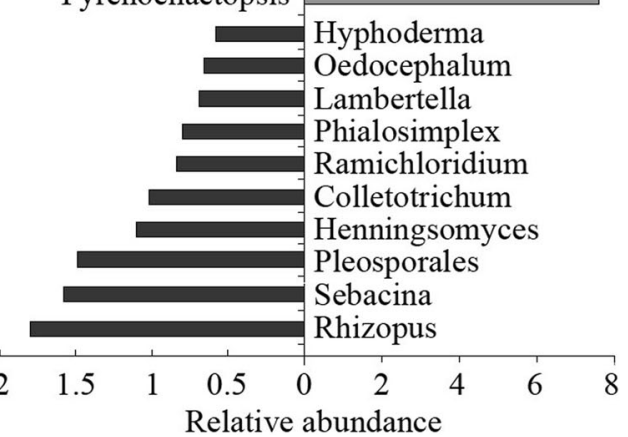

Fig. 4 Comparison of the relative abundance of foliar fungal endophytes between $V$. vinifera cV. Red Globe (RG) and V. amurensis cV. Shuangyou (SY). a Venn diagram of foliar fungal endophytes recovered from leaves of RG and SY. The numbers of overlapping and non-overlapping fungi at genus level are represented in the circles. b Relative abundance of significantly different genera between RG and SY based on Metastats analysis. Asterisks indicate statistically significant differences $(P<0.05)$. c Differentially abundant genera in two cultivars

structural characteristics for most fungal endophytic species and become vulnerable to a diverse group of fungal species as compared with mature leaves.

Endophytic fungi from Chinese wild grape are considered as potential candidate biocontrol agents. For instance, we found some strains of Alternaria that are known to be effective against Plasmopara viticola in grape (Musetti et al. 2006) and strains of Phoma that act as biocontrol agents of weeds (Zhou et al. 2004). Several studies showed that $M$. verrucaria functions as a bioherbicide against bacteria (Zou et al. 2011) and a nematicide against root-knot nematode (Fernández et al. 2001). Interestingly, four out of seven fungal endophytes isolated from young leaves inhibited the growth of the pathogen Colletotrichum lindemuthianum in lima bean (López-González et al. 2017). Additionally, PujadeRenaud et al. (2019)'s study reported that endophytes from wild rubber trees can act as antagonists of the pathogen Corynespora cassiicola, suggesting that some endophytes from wild plants are promising candidates as biocontrol agents.

Most fungi isolated as endophytes may be latent pathogens within the host tissue. It seemed to reflect the life history strategies of fungal species from mutualistic to parasitic (Delaye et al. 2013). Although endophytes have shown that they can protect their host against abiotic and biotic stress, stress condition, excessive humidity, and poor nutrition can clearly shift the interaction relationship from endophytes to pathogenic fungi (Photita et al. 2004; Romero et al. 2001). Additionally, although the grape leaves look healthy, they have been colonized by pathogens that may cause disease until suitable conditions. In this study, we identified two important genera (Botryosphaeria and Erysiphe) from young leaves of $V$. amurensis cv. Shuangyou. Among these, Botryosphaeria dothidea is the causal agent of grapevine canker (Phillips 1998) and Erysiphe necator cause grape powdery mildew (Gadoury et al. 2012). Further research is needed to clarify and minimize negative impact of endophytes on plants as biocontrol agents.

\section{Conclusion}

Our results showed that endophytic fungal community is quite different in domesticated and wild grape as well as in young and old leaves of the same shoot. Some of these endophytes are already known as biocontrol agents, possibly explaining the enhanced resistance to fungal pathogens of $V$. amurensis. Future investigation of the richness and diversity of endophytes from different sites and more wild grapes will likely provide a deeper understanding of the endophytic colonization, distribution, and their effective role in plant fitness.

\section{Supplementary information}

Supplementary information accompanies this paper at https://doi.org/10. 1186/s13213-020-01574-9.

Additional file 1: Figure S1. Rarefaction curve of observed OTUs from young and mature leaves of $V$. vinifera $\mathrm{cV}$. Red globe and $V$. amurensis $\mathrm{CV}$. Shuangyou. Figure S2. Principal coordinate analysis (PCOA) plot based 
on the weighted UniFrac distance at different cultivars and foliar ages. Points that are closer together on the ordination have communities that are more similar. Red: RG young leaves; green: RG mature leaves; bule: SY young leaves; purple: SY mature leaves. RG: V. vinifera cv. Red globe; SY: V. amurensis cv. Shuangyou. Figure S3. Numbers of endophytic fungal genera in young leaves (LY) and mature leaves (ML) of RG and SY. Table S1. Sequencing data of all samples in this study. Table S2. Relative abundances of endophytic fungus at genus level. Values represent mean relative abundances for each family and sample type. RG: $V$. vinifera $\mathrm{cV}$. Red globe; SY: V. amurensis cv. Shuangyou; YL: young leaves; ML: mature leaves. Table S3. Host-specificity of endophytes of endophytic fungal genera in young leaves (LY) and mature leaves (ML) of $V$. vinifera $\mathrm{cV}$. Red globe and $V$. amurensis $\mathrm{cv}$. Shuangyou.

\section{Acknowledgements}

We thank editors of Annals of Microbiology and the anonymous reviewers for thoughtful comments on a draft. This work was supported by the National Natural Science Foundation of China (31501740).

\section{Authors' contribution}

YF and LG carried out all experiments and wrote this manuscript. PC participated in the design of the study and performed the statistical analysis. ZL designed the experiment. All authors read and approved the final manuscript.

\section{Ethics approval and consent to participate}

This article does not contain any studies with human participants or animals performed by any of the authors.

\section{Consent for publication}

Not applicable.

\section{Competing interests}

The authors declare that they have no conflict of interest.

\section{Author details}

${ }^{1}$ College of Forestry, Northwest A\&F University, Yangling 712100, Shaanxi, China. ${ }^{2}$ State Key Laboratory of Crop Stress Biology in Arid Areas, College of Horticulture, Northwest A\&F University, Yangling 712100, Shaanxi, China.

Received: 22 October 2019 Accepted: 23 April 2020

Published online: 15 May 2020

\section{References}

Abarenkov K, Henrik Nilsson R, Larsson KH, Alexander IJ, Eberhardt U, Erland S, Høiland K, Kjøller R, Larsson E, Pennanen T, Sen R, Taylor AFS, Tedersoo L, Ursing BM, Vrålstad T, Liimatainen K, Peintner U, Köljalg U (2010) The UNITE database for molecular identification of fungi-recent updates and future perspectives. New Phytol 186:281-285

Arnold AE, Lutzoni F (2007) Diversity and host range of foliar fungal endophytes: are tropical leaves biodiversity hotspots? Ecology 88:541-549

Arnold AE, Mejía LC, Kyllo D, Rojas El, Maynard Z, Robbins N, Herre EA (2003) Fungal endophytes limit pathogen damage in a tropical tree. Proc Natl Acad Sci USA 100:15649-15654

Bae H, Sicher RC, Kim MS, Kim SH, Strem MD, Melnick RL, Bailey BA (2009) The beneficial endophyte Trichoderma hamatum isolate DIS $219 \mathrm{~b}$ promotes growth and delays the onset of the drought response in Theobroma cacao. J Exp Bot 60:3279-3295

Baltruschat H, Fodor J, Harrach BD, Niemczyk E, Barna B, Gullner G, Janeczko A, Kogel KH, Schafer P, Schwarczinger I, Zuccaro A, Skoczowski A (2008) Salt tolerance of barley induced by the root endophyte Piriformospora indica is associated with a strong increase in antioxidants. New Phytol 180:501-510

Broeckling CD, Broz AK, Bergelson J, Manter DK, Vivanco JM (2008) Root exudates regulate soil fungal community composition and diversity. Appl Environ Microbiol 74:738-744

Campisano A, Pancher M, Puopolo G, Puddu A, Lòpez-Fernàndez S, Biagini B, Pertot I (2015) Diversity in endophyte populations reveals functional and taxonomic diversity between wild and domesticated grapevines. Am J Enol Viticult 66:12-21
Caporaso J, Kuczynski J, Stombaugh J, Bittinger K, Bushman FD, Costello EK, Fierer N, Gonzalez Penz A, Goodrich JK, Gordon Jl, Huttley GA, Kelley ST, Knight D, Koenig JE, Ley RE, Lozupone CA, McDonald D, Muegge BD, Pirrung M, Reeder J, Sevinsky JR, Turnbaugh PJ, Walters WA, Widmann J, Yatsunenko T, Zaneveld J, Knight R (2010) QIIME allows analysis of high-throughput community sequencing data. Nat Methods 7:335-336

Casieri L, Hofstetter V, Viret O, Gindro K (2009) Fungal communities living in the wood of different cultivars of young Vitis vinifera plants. Phytopathol Medite 48:73-83

Chen J, Bittinger K, Charlson ES, Hoffmann C, Lewis J, Wu GD, Collman RG, Bushman FD, Li H (2012) Associating microbiome composition with environmental covariates using generalized UniFrac distances. Bioinformatics 28:2106-2113

Delaye L, García-Guzmán G, Heil M (2013) Endophytes versus biotrophic and necrotrophic pathogens-are fungal lifestyles evolutionarily stable traits? Fungal Divers 60:125-135

Dissanayake AJ, Purahong W, Wubet T, Hyde KD, Zhang W, Xu H, Zhang G, Fu C, Liu M, Xing Q, Li X, Yan J (2018) Direct comparison of culture-dependent and culture-independent molecular approaches reveal the diversity of fungal endophytic communities in stems of grapevine (Vitis vinifera). Fungal Divers 90:85-107

Dixon R, Hartmann A (2017) Novel insights into ecological distribution and plant growth promotion by nitrogen-fixing endophytes-how specialised are they? Env Microbiol Rep 9:179-181

Edgar RC (2013) UPARSE: highly accurate OTU sequences from microbial amplicon reads. Nat Methods 10:996-998

Edgar RC, Haas BJ, Clemente JC, Quince C, Knight R (2011) UCHIME improves sensitivity and speed of chimera detection. Bioinformatics 27:2194-2200

Espinosa Garcia FJ, Langenheim JH (1990) The endophytic fungal community in leaves of coastal redwood population diversity and spatial patterns. New Phytol 116:89-97

Fernández C, Rodriguez-Kábana R, Warrior P, Kloepper JW (2001) Induced soil suppressiveness to a root-knot nematode species by a nematicide. Biol Control 22:103-114

Fróhlich J, Hyde KD, Petrini O (2000) Endophytic fungi associated with palms. Mycol Res 104:1202-1212

Gadoury DM, Cadle-Davidson LANCE, Wilcox WF, Dry IB, Seem RC, Milgroom MG (2012) Grapevine powdery mildew (Erysiphe necator): a fascinating system for the study of the biology, ecology and epidemiology of an obligate biotroph. Mol Plant Pathol 13:1-16

García E, Alonso Á, Platas G, Sacristán S (2013) The endophytic mycobiota of Arabidopsis thaliana. Fungal Divers 60:71-89

González V, Tello ML (2011) The endophytic mycota associated with Vitis vinifera in central Spain. Fungal Divers 47:29-42

Horton MW, Bodenhausen N, Beilsmith K, Meng D, Muegge BD, Subramanian S, Vetter MM, Vilhjálmsson BJ, Nordborg M, Gordon JI, Bergelson J (2014) Genome-wide association study of Arabidopsis thaliana's leaf microbial community. Nat Commun 5:5320

Husband R, Herre EA, Young JPW (2002) Temporal variation in the arbuscular mycorrhizal communities colonising seedlings in a tropical forest. FEMS Microbiol Ecol 42:131-136

Kernaghan G, Mayerhofer M, Griffin A (2017) Fungal endophytes of wild and hybrid Vitis leaves and their potential for vineyard biocontrol. Can J Microbiol 63:583-595

Kolton M, Graber ER, Tsehansky L, Elad Y, Cytryn E (2017) Biochar-stimulated plant performance is strongly linked to microbial diversity and metabolic potential in the rhizosphere. New Phytol 213:1393-1404

Kuldau G, Bacon CW (2008) Clavicipitaceous endophytes: their ability to enhance resistance of grasses to multiple stresses. Biol Control 46:57-71

Lin X, Tfaily MM, Steinweg JM, Chanton P, Esson K, Yang ZK, Chanton JP, Copper W, Schadt CW, Kostka JE (2014) Microbial community stratification linked to utilization of carbohydrates and phosphorus limitation in a boreal peatland at Marcell Experimental Forest, Minnesota, USA. Appl Environ Microbiol 80:3518-3530

López-González RC, Gómez-Cornelio S, Susana C, Garrido E, Oropeza-Mariano O, Heil M, Partida-Martinez LP (2017) The age of lima bean leaves influences the richness and diversity of the endophytic fungal community, but not the antagonistic effect of endophytes against Colletotrichum lindemuthianum. Fungal Ecol 26:1-10

Magoč T, Salzberg L (2011) FLASH: fast length adjustment of short reads to improve genome assemblies. Bioinformatics 27:2957-2963 
Martini M, Musetti R, Grisan S, Polizzotto R, Borselli S, Pavan F, Osler R (2009) DNA-dependent detection of the grapevine fungal endophytes Aureobasidium pullulans and Epicoccum nigrum. Plant Dis 93:993-998

Materatski P, Varanda C, Carvalho T, Dias AB, Campos MD, Rei F, do Rosário Félix M (2019) Spatial and temporal variation of fungal endophytic richness and diversity associated to the phyllosphere of olive cultivars. Fungal Biol 123:6676

Musetti R, Vecchione A, Stringher L, Borselli S, Zulini L, Marzani C, D'Ambrosio M, di Toppi LS, Pertot I (2006) Inhibition of sporulation and ultrastructural alterations of grapevine downy mildew by the endophytic fungus Alternaria alternata. Phytopathology 96:689-698

Nettles R, Watkins J, Ricks K, Boyer M, Licht M, Atwood LW, Peoples M, Smith RG, Mortensen DA, Koide RT (2016) Influence of pesticide seed treatments on rhizosphere fungal and bacterial communities and leaf fungal endophyte communities in maize and soybean. Appl Soil Ecol 102:61-69

Oono R, Lefèvre E, Simha A, Lutzoni F (2015) A comparison of the community diversity of foliar fungal endophytes between seedling and adult loblolly pines (Pinus taeda). Fungal Biol 119:917-928

Pancher M, Ceol M, Corneo PE, Longa CMO, Yousaf S, Pertot I, Campiano A (2012) Fungal endophytic communities in grapevines (Vitis vinifera L.) respond to crop management. Appl Environ Microb 78:4308-4317

Phillips AJL (1998) Botryosphaeria dothidea and other fungi associated with excoriose and dieback of grapevines in Portugal. J Phytopathol 146:327-332

Photita W, Lumyong S, Lumyong P, McKenzie EHC, Hyde KD (2004) Are some endophytes of Musa acuminata latent pathogens? Fungal Divers 16:131-140

Pujade-Renaud V, Déon M, Gazis R, Ribeiro S, Dessailly F, Granet F, Chaverri P (2019) Endophytes from wild rubber trees as antagonists of the pathogen Corynespora cassiicola. Phytopathology 109:1888-1899

Romero A, Carrion G, Rico-Gray V (2001) Fungal latent pathogens and endophytes from leaves of Parthenium hysterophorus (Asteraceae). Fungal Divers 7:81-87

Sadeghi F, Samsampour D, Seyahooei MA, Bagheri A, Soltani J (2019) Diversity and spatiotemporal distribution of fungal endophytes associated with citrus reticulata cv. siyahoo. Curr Microbiol 76:279-289

Sanchez-Azofeifa A, Oki Y, Fernandes GW, Ball RA, Gamon J (2012) Relationships between endophyte diversity and leaf optical properties. Trees 26:291-299

Sherameti I, Tripathi S, Varma A, Oelmueller R (2008) The root-colonizing endophyte Piriformospora indica confers drought tolerance in Arabidopsis by stimulating the expression of drought stress-related genes in leaves. Mol Plant-Microbe Interact 21:799-807

Varma A, Verma S, Sahay N, Butehorn B, Franken P (1999) Piriformospora indica, a cultivable plant growth promoting root endophyte. Appl Environ Microb 65: 2741-2744

Wan R, Hou X, Wang X, Qu J, Singer SD, Wang Y, Wang X (2015) Resistance evaluation of Chinese wild Vitis genotypes against Botrytis cinerea and different responses of resistant and susceptible hosts to the infection. Front Plant Sci 6:854

Wang Y, Liu Y, He P, Chen J, Lamikanra O, Lu J (1995) Evaluation of foliar resistance to Uncinula necator in Chinese wild Vitis species. Vitis 34:159-164

White TJ, Bruns T, Lee S, Taylor J (1990) Amplification and direct sequencing of fungal ribosomal RNA genes for phylogenetics. In: Innis MA, Gelfand DH, Sninsky JJ, White TJ (eds) PCR protocols: a guide to methods and applications. Academic Press, San Diego, pp 315-322

Yu Y, Xu W, Wang J, Wang L, Yao W, Yang Y, Xu Y, Ma F, Du Y, Wang Y (2013) The Chinese wild grapevine (Vitis pseudoreticulata) E3 ubiquitin ligase Erysiphe necator-induced RING finger protein 1 (EIRP1) activates plant defense responses by inducing proteolysis of the VpWRKY11 transcription factor. New Phytol 200:834-846

Zhou L, Bailey KL, Derby J (2004) Plant colonization and environmental fate of the biocontrol fungus Phoma macrostoma. Biol Control 30:634-644

Zou X, Niu S, Ren J, Li E, Liu X, Che Y (2011) Verrucamides A-D, antibacterial cyclopeptides from Myrothecium verrucaria. J Nat Prod 74:1111-1116

\section{Publisher's Note}

Springer Nature remains neutral with regard to jurisdictional claims in published maps and institutional affiliations.

Ready to submit your research? Choose BMC and benefit from:

- fast, convenient online submission

- thorough peer review by experienced researchers in your field

- rapid publication on acceptance

- support for research data, including large and complex data types

- gold Open Access which fosters wider collaboration and increased citations

- maximum visibility for your research: over $100 \mathrm{M}$ website views per year

At BMC, research is always in progress.

Learn more biomedcentral.com/submissions 